\title{
Courage to Trust-Discussion of Moral Personality Built on the Confucian Ethics
}

\author{
Lei Kang (Guangdong University of Foreign Studies) \\ Ying Qiu (Guangdong University of Foreign Studies) \\ Tie Zheng (Guangdong University of Foreign Studies) \\ Anne Rubienska (Guangdong University of Foreign Studies)
}

\section{Introduction to Confucian Ethics of Xin}

Though the Analects is not the only literature to study Confucius's thoughts, nor does it include all the theories by Confucius, the book indeed reveals Confucius's main views on ethics. Through the joint efforts by Confucius and his students, a complete set of ethical values for purpose of building noble characters for personal development was established some 2500 years ago in China, which however were harnessed by rulers of different times to set patriarchal hierarchy as social order and means of governance. Resorting to ritual and music as main administrative guideline, Confucius believed that ethical guidance and virtue development should be the fundamental task for any nation, and people need to be educated to show their reverence for destiny and respect for ancestors, which was later regarded as a convention similar to religious attitude among Chinese people. Positioning the virtue of benevolence (Ren) as the core, Confucius proposed several cardinal virtues as essential ethic elements for one's value system, including filial piety, loyalty, forgiveness, intelligence, bravery, courtesy, mediocrity, humility, generosity, trustworthiness, etc. (Wan 2009, 80). However, the way these virtues were expounded and discussed in the Analects led us to the question: Are these virtues only moral principles and attitudes, or do they imply specific conduct code or behavioural norms as well?

According to Yang Bojun (1980, 257-258), the word "Xin" has been mentioned in the Analects for 38 times, more frequent than the words for "filial piety", "justice" and "loyalty"; therefore, we could see that the moral value of Xin was thought highly by Confucius. With a literal meaning of "belief", the word Xin has mostly been interpreted as "being honest, reliable, credible and trustworthy", one of the cardinal Confucian ethics. However, as we studied the Analects, we found that there are four different connotations of the word "Xin" in Chinese: Firstly, it means "trustworthy" and "creditability", which appeared 24 times in the book, for example, in the sentence of "how can one make friends without credible words?" (in Chapter Xue Er); secondly, it means 
"to believe", "being trusting", which appeared for 11 times, for example, in the sentence of "shall we listen to his words and believe in his deeds?" (in Chapter Gong Ye Chang); thirdly, it is used as an adjective or an adverb twice, meaning "really" and "indeed", i.e., in the sentence of "if it indeed turned out to be that the king does not behave like a king" (in Chapter Yan Yuan), and in the sentence of "Really? Didn't that master talk, did not laugh, nor did he take other's belongings?" (in Chapter Xian Wen); and, finally, the meaning of "making one believe" appeared just once, in the sentence of "make his friends believe in him" (in Chapter Gong Ye Chang).

Based on the four categories of the meanings of Xin, we came to the fact that among all the possible meanings of the word "Xin" shown in the Analects, "being trustworthy" is the most frequently used connotation, followed by the meaning of "to trust", "to believe". Other meanings are simply the inferred or extended meaning of "honesty" and "trust". Hence, two relevant but different meanings of the word "Xin" expressed in the Analects stand out.

The word "Xin" mentioned by Confucius so many times in the Analects referred to a virtue with two aspects: to constantly maintain enduring characteristics of honesty and integrity, and to take trusting attitudes and actions upon others, i.e. to have constant trust on others. The first aspect refers to the extent to which others can expect predictability in one's behaviour in terms of what is "normally" expected of a person's action in good faith. The second aspect of trust is the willingness of one party in a relationship to make himself or herself vulnerable to another party. This kind of indifference between the subject and the object of ethical conduct is very common in Confucian works, or rather ancient Chinese works, due to linguistic reasons. It is just like the specific ethical standards of Ren (benevolence) by Confucius, which indicates both the self-aspect and the otherness-aspect. Benevolence, as required by Confucius, refers to helping others to grow, to achieve and to feel content, after one has successfully developed himself (Chen 2012, 66-68). Similarly, the value of Xin actually sees a congruence of two subvalues: one is the cognition-oriented virtue inwards to self; the other is more action-oriented norm outwards to otherness.

Therefore, the value of Xin is based on a social performance norm among friends or peers, stating clearly the ethical imperative of an authentic and reliable interpersonal relationship. The ethical value of Xin lies in the fact that it is not only a virtue possessed by individuals, but rather a mutually committed obligation. Once personalized as trait and accepted as behaviour, the value of Xin with its two aspects can be seen as an attribute of personality, which is formed from two opposing sources.

The two ethical aspects of the value of Xin will be thoroughly discussed, underpinned by citations from the Analects and other major thoughts of Confucius. The analysis of the value basis of the trait and 
behavioural aspects of Xin may bring up new ideas in fostering ethical behaviour.

\section{The Fusion of Credibility into Self}

Honesty and credibility, as one of the basic interpersonal norms, has long been respected and sought after. As mentioned in the Chapter of Wei Ling Gong, "a noble man should bear justice as his nature, follow rites to practice it, act humbly to show it, and behave honestly to gain it", Confucius thought highly of people who was honest and trustworthy, and the person who possessed such trait and behaved in such way was regarded as noble in Confucius time. Confucius once said, "If a person is not reliable, how can we know he is able to do anything? It is just like a chariot without shaft, a cart without thill, how can we get along with them?" (in Chapter Wei Zheng). Therefore, in Confucius's mind, a person without credibility cannot be regarded as a social man. Credibility is just like that critical connecting and guiding device for a cart, without which the cart is dysfunctional. In this vivid analogy, Confucius showed his attitude toward credibility and regarded it as one of the basic ethics for being a socially accepted man. In the Analects, we could find that Confucius set credibility as one of the learning contents for his students: "I have four major things to teach, i.e. reading, practicing, being loyal and being trustworthy." (in Chapter Shu Er) From this we could see that intellectual knowledge, practical skills, honest treatment to others and credibility are the most essential things for his students to master. Therefore, when one of his students, Zi Zhang, later asked Confucius how to behave, he told the student that the priority was "to talk in a loyal and reliable manner" (in Chapter Wei Ling Gong). For interpersonal relations, Confucius asserted that credibility was the key to any social interaction. In the Chapter of Xue Er, there were three questions asked by one of his famous student, Zeng Zi, to urge people to do self-examination three times a day, and to reflect whether his behaviour was up to the ethical standards. Among which one of the questions is to ask "are you not reliable in any way when interacting with your friends today?" Confucian ethics emphasize greatly on credibility and view it as the one of the indispensible performance norm for social activities.

Important as it is, credibility is not only a social norm to follow, or a compliance to commit. We are able to internalize such an important ethical standard into our trait as one of the important constituents for moral personality and therefore, stimulate correspondent ethical behaviour. The forming of moral personality can be explained from the socio-psychological perspective. In socio-psychology, the concept of self is much related to selfawareness or self-cognition. Self-cognition refers to the understanding and assumption of one's behaviour, motives, interest, etc., and is somehow realized through self-perception and social feedback. The concept of self-perception 
proposed by Bem pointed out that people could infer their attitudes and motives through observing their actions and situations (Bem 1967). Hence, attitudes are formulated and used to make sense of certain behaviour. Besides self-perception, social feedback is another source for us to gain knowledge of self, and is, to some extent, supplementary to self-perception. The observation of our behaviour by others usually helps us make better judgment towards ourselves. Even though social feedback may exaggerate, neglect or distort some information of us, once we have been evaluated and depicted in certain way by others, it is very likely for us to just follow this identity labelled by social feedback, and behave accordingly. This also explains why people would always behave as expected by others. Therefore, the formation of one's moral personality, besides inherent traits, is closely related to socio-cultural information received by individuals, such as social learning processes, others' evaluation, and one's perception of others' evaluation.

As we have stated above, one basic meaning of Xin proposed by Confucian ethics is to maintain one's credibility, mostly referring to a kind of interactive ethics abide by friends. The reason that Confucius emphasized so much on "being trustworthy with friends" can be explained by the different firmness of the five cardinal relationships described by Confucius. In Confucius's mind, the relationship with friends is the least solid one (Zhang 2011). Consequently, the concept of Xin is developed in accordance with the uncertainty of such relations. How could people get along well with someone outside their own family, and what kind of social norm to observe in a more volatile and uncertain social relationship than that of relatives? Confucius answered this question by suggesting keeping some important traits intact and some socializing principles stable, which is the only way to build a common ground for uncertain social relationships.

However, what traits or socializing principles will individuals choose to follow? Some people would take on same traits and adopt same socializing norms for all friends, while others may prefer choosing different interactive rules and representing varied personality traits with different social groups. Views from social cognition, phenomenology and social constructivism all suggest that individual's interpretation of his social experience and perception of other's evaluation of him have great impact on the formation of his personality. Therefore, one's credibility among friends is a prerequisite as well as the consequence of any social interaction. As Confucius said, "respect your work and be trustworthy", one's conscientiousness and credibility are the premise to gain others' respect and trust. Besides, Confucius also stressed the importance of "being prudent and credible". To keep one's integrity is to gain ethical currency for more social interactions. Without such currency, one cannot survive in his social circles, let alone engaging in more social activities. Hence, it is in the need of social interaction that one has to develop credibility as his personality trait in exchange of others' trust. Social interaction will 
become more effective if there is a clearly perceivable commonality between us and them, which is the cornerstone for further development of social relationships. Of course, one may argue that such commonality could also come from other Confucian ethics than Xin, such as benevolence (Ren), justice (Yi), courtesy (Li), intelligence (Zhi). However, these ethics may have too many connotations, which can be perceived very differently, and become difficult to measure. Consequently, these values are not easily translated to instrumental values to guide specific behavior, nor are they easily recognized or followed by different demographic and social groups. In contrast, the test of being trustworthy or not is relatively simple, and can be readily comprehensible and equally practical for people from different social backgrounds. As long as "a man keeps to his words" and fulfils his promises, he is deemed to be credible.

Hence, as a moral personality, the first attribute of Xin is the enduring trustworthy characteristics, or credibility. Yet, such trait is built upon interactions with others during a social learning process of absorbing vicarious experience, others' expectations, evaluations and reinforcement, and other social information. This process also explains how environment may influence the formation of one's personality and a fusion competence acquired from social learning ability (Bandura 2015). Positive and proactive learning experiences may help transfer others' credible and authentic characters into us, while negative and unfaithful interactions with others may bring dishonest and incredibility into our character. Therefore, fusion from others is a major source of moral personality and the virtuous traits or characters fused from others are important constituents for one's moral personality. Vital as it is, credibility has long been attentively discussed and emphasized in China; however, it is the second aspect of the ethical value of Xin that has aroused more interest in our research, i.e., the trait and action to trust as expressed by Confucius in the value of Xin. Compared to the self-construction of the trait of credibility in an inward process of fusing others' traits, the outward process of helping others' self-construction of credibility may be more challenging, and requires more courage and intelligence. Unfortunately, this second aspect of Xin has somehow been overlooked in China for a long time.

\section{The Fission of Trust into Otherness}

Confucius emphasized the importance of promoting trust among people. In the Chapter of Gong Ye Chang of the Analects, there is a record of his conversation with his students, Zi Lu and Yan Yuan. Confucius said, "We need to settle down the elderly, to trust friends and to take care the young". Similar thought of the great harmony was expressed in a Confucian book, "On s" ( $L i$ Yun Pian) (Wang 1983, 191-192). To be brave enough to trust our friends clearly showed Confucius's ideal society where people can trust each other and there is no longer hatred or suspicion in social interactions. In the Chapter 
of Tai Bo, Confucius expressed his discontent towards someone who was "arrogant but not just, ignorant but not modest, and trust nobody", which refers to a person who has no intellect is reluctant to trust others. A society full of such people must been a place with calamity and tumult. In the Chapter of Yan Yuan, Confucius tried to clarify approaches to dispelling the bewilderment of people's mind and he restated, "to devote and to trust as the primary approach, coupled with justice, this is the way to promote ethics among people." In his views, Confucius has always believed that maintaining one's integrity in an unbiased way, and being courageous to trust others are the most essential part of self-improvement, and the effective method to upgrade one's morality. Beside, self-enhancement, in the Chapter of Xian Wen, Confucius also stressed a credo for making friends or other social interactions: "no pre-assumption of others' deception, no pre-set speculation of others' dishonest; only when one can predict such bad behaviour in an accurate way, can he be truly wise". Of course, courage does not equal to rashness, but here Confucius tried to remind us that in the process of social interactions among friends or even strangers, the common ground for possible collaboration couldn't be built upon the illusory assumption of the other party's evil intention. In the Chapter of $\mathrm{Zi} \mathrm{Lu}$, Confucius pointed out more clearly that "if the leaders respect rituals, then every ordinary people would not dare to disrespect rituals; if the leaders prefer justice, then every ordinary people would not dare to disregard justice; if the leaders tend to trust, then every ordinary people would not dare to be indifferent to trust." "Tend to trust" or "prefer to trust" refers not only to one's credibility, but also to one's trusting character. To cast a full trust on self, as well as on others is an ethical competence, which is not innate in everyone, but acquired after social interactions, and which takes courage and wisdom to develop. If the leader is determined to delegate certain tasks to others, then he'd better give his full support or trust to them, in exchange of others' full commitment to the tasks and genuine loyalty to the leader-member relations. Only by so doing, believed by Confucius, could leaders gain wholehearted support, attract talented personnel, harvest people's respect, and embrace legitimate reign over the nation. Therefore, the formation of Confucian's gentleman or nobleman (Jun Zi) requires moral personality, who "has justice as the essence" of his personality, "uses rituals to practice it", "behaves in a humble way", and finally, the moral personality is not completely formed unless "one can trust others." In the Analects, this sentence clearly stated that the function of trust is to complete a moral personality. Even if one possess all other important ethical traits, if he could not be trustworthy or fail to have the courage to trust others, his moral personality is not complete, for his ethics remain at theoretical level, and cannot be tested in social interactions. One of the most readily identifiable ethical traits and behaviour in practice is the competence to trust. 
Of course, Confucius also realized the potential risks of "trusting one's behaviours only according to what he said", hence he proposed six learning outcomes: learning the ethical value of benevolence helps one become more philanthropic and forgiving, whereas it also makes one easily mocked and fooled; learning the ethical value of intelligence helps one become more knowledgeable and wise, whereas it may also lead to nowhere because of the diverse interests without focused research; learning the ethical value of courtesy/rite helps one become more modest and humble, whereas it also tends to make one conform too rigidly; learning the ethical value of justice makes one candid and straightforward, whereas it may also lead to a negative function and easily hurt others without even noticing it; learning the ethical value of bravery helps one become more tough and assertive, whereas it may also lead to rudeness and arbitrariness; learning the ethical value of trust helps one maintain his social norms and integrity, whereas it also makes one vulnerable to deception.

Among these "Six Malpractices" (Liu Bi), the negative impact of the malpractice of trust is most dangerous and costly; however, if a society gave up this ethical value because of its possible negative effect due to malpractice, then the cost for making this society function properly, i.e., social cost, would be even higher. Confucius has already seen the rationale of this paradoxical Game Theory, a kind of ethical dilemma of "to trust or not to trust" faced by human beings; therefore, the moral personality focusing on the value of Xin, on trusting character and on the courage to trust, proposed by Confucius, reflects his utmost courage to trust in human nature and his unmatchable wisdom in perceiving social interactions. That is exactly a courage described in his famous statement: "Benevolence arrives when I myself wish to become benevolent". Such courage of being trusting in human nature is not based on overoptimistic expectation of a utopian society characterized by Great Harmony, but rather on a realistic analysis of the most cost-effective method of social interaction, and a practical premise of establishing interpersonal psychological contract upon which social norms can then be built. Confucius once mentioned his own ethical principle governing his behaviour is "to be consistently honest to self and forgiving to others", which reflects again the two orientations in practicing all Confucian ethics: toward self and toward others. Similarly, the ethical value of Xin, or trust, also emphasizes that the processes to develop such virtue and to encourage such behaviour all start from within, the self, and gradually extend towards outside, the otherness.

As above analysed, the value foundation for Xin is to "do as you would be done by", but what determine the degree to which one person feels assured that another will not take malevolent or arbitrary actions? Trust is a historydependent process (familiarity) based on relevant but limited samples of experience (risk) (Robbins 2012, 395-396). When a person has a positive expectation that another will not-through words, actions, or decisions-act 
opportunistically, he or she must first of all have confidence in this positive expectation. The psychological basis for one's willingness to trust results in three types of trust: deterrence-based trust built upon the coercive power of legal institution, knowledge-based trust built upon the degree of acquaintance among interpersonal relations, and identification-based trust built upon commonly shared values, faith and norms. As Fukuyama mentioned in his study of trust in different nations (Fukuyama 2001), China has been regarded as a nation whose social operation relies largely on knowledge-based trust. The differential or "ripple" pattern of kinship and other social relations suggested by Chinese sociologist, Fei Xiaotong (2007), also reveals the fact that the degree of trust to others will gradually decrease as the knowledge of them reduced from core to peripheral relations. Giddens used the concept of "disembedding" to describe the modernity of a society (2011, 22-25). In traditional society, people at closer distance may have many chances for direct communication and interaction, while as the development of popular and interactive social media, modern society has been extended enormously in terms of time and space. Currencies, symbolism, English, Internet, etc. are all tools helping man in a modern society become dis-embedded. In such a disembedding society, people are estranged from their former social activities and separated from usual domains of their previous social interactions. For example, one's friend circle might be redefined and reconstructed by embracing some previously unfamiliar domains consisted of government, enterprises and intellectuals. The dis-embedding might be a periodical result of social changes, following the natural trend of the evolution of any social organization. However, when this social change of dis-embedding continues, would it eventually change people's affective and normative commitment to social life? If the actual change in social nexus saw no base of trust to underpin it, the anomie of the society would worsen in a dis-embedded human relationship. In any unfamiliar interpersonal relations, it is presumably easier to take a distrust attitude, which wouldn't expend too much psychological energy; however, in a dis-embedding society, believing the words and actions of a completely unknown person demands more intellectual ability and emotional labor, and requires strong psychological capital or willpower. Such capacity or competence is what described by Confucius as the courage to trust.

Therefore, when we are able to trust others, we are in fact transferring part of our wisdom of judgment and courage of upholding positive affect into others, which is a process of fission of the traits and behavior of self into that of otherness. The purpose of such outward-bound fission process is to actively construct a common ground for mutual knowledge, and to contribute to possibilities of identification before seeking one. Instead of asking others to behave in a trustworthy way and to trust us, we need to be able to trust first, though in a discreet way. When we are determined to trust others, to trust their traits to be consistent, and to trust what they said and what they did are 
predictive to his future behaviour, we have already altered the intersubjectivity between us and them. The expressed attitude and conducted behavior of one party would have a positive impact on the other party's perception of this interrelationship, hence may impel a reciprocal trust. A conglomerated inter-subjectivity erected upon the fusion and fission of Xin may lay a more solid psychological foundation for mutual trust.

\section{Discussion}

The fusion-fission relation used to describe the constitution of intersubjectivity is not our original idea. In his books and papers on aesthetic and traditional Chinese philosophy, Chinese scholar Luan Dong has already discussed such a phenomenon, and proposed this bidirectional process of interactions between self and otherness (Luan 2010). Here we borrowed the concept and applied it to the process of incorporating the ethical value of Xin into the establishment of moral personality. The fusion of Xin (credibility) describes a process of absorbing and assimilating valuable traits and behaviours from otherness into self (Hua-Ta), while the fission of Xin (trust) describes a process of an opposite direction, a process of dissolving and disseminating valuable traits and behaviours from self into otherness (TaHua), which in our view requires more psychological dynamics, i.e. a courage, or rather, a moral competence to trust.

Addressed as "moral judgment" by Kohlberg, moral cognition ability, i.e., the ability to make moral judgments and take action accordingly, is seen as inseparable from individual's ability in democratic decision-making and communication by German psychologist Georg Lind. Therefore, Lind developed the concept of "moral-democratic competence", or "moral competence", in short. Defined as "the ability to solve conflicts and dilemmas on the basis of shared moral principles and accepted rules through thinking and discussion, rather than through violence, deceit and power" (Lind 2009, 46), moral competence is built upon values and into personality. Therefore, we'd discuss how fusion and fission of the value of Xin bridges ethical values and moral personality.

\subsection{From Confucian Ethics to Moral Personality}

Values represent basic convictions that "a specific mode of conduct or endstates of existence is personally or socially preferable to an opposite or converse mode of conduct or end-states of existence" (Rokeach 1973, 5). They contain a judgemental element in that they carry an individual's ideas as to what is right, good, or desirable. Values have both content and intensity attributes. The content attribute says a mode of conduct or end-states of existence is important, and the intensity attribute specifies how important it is (Robbins \& Jugde 2012, 145-146). When we rank an individual's values in 
terms of their intensity, we obtain that person's value system. Though being more cognition-oriented than behaviour-oriented, values lay the foundation for our understanding of people's attitudes and motivation and influence our perception. As a result, they may influence our attitudes and behaviour. The Rokeach Value Survey consists of two sets of values, i.e. terminal values and instrumental values. Instrumental values are preferable modes of behaviour, or means of achieving the terminal values, i.e. the goals a person would like to achieve during his or her lifetime.

The application of values to judge one's personality can be traced back into the beginning of Zhou dynasty, Emperor Zhou Wen (BC 1152 - BC 1056) already mentioned that whether a candidate is suitable for certain position, personnel officials need to examine candidates' moral traits through observing their emotions. How they expressed their feelings of happiness, anger, desire, fear and sadness may reveal their values and moral traits. Later in the ruling of Emperor Zhou Cheng (BC 1055 - BC 1021), Ji Dan, the royal uncle developed a complete set of ritual and music for the purpose of cultivating moral temperament and character. Strict ritual requirement and appropriate music production were used as effective methods to build moral personality in archaic times. However, the systematic study on moral personality began with Confucius's efforts, and the whole system of Confucian ethic served to foster moral personality.

The Analects and other Confucian works led us to the recognition of the value of Ren (benevolence) as a terminal value, and other four basic ethical values, Yi, Li, Zhi and Xin, are set as four instrumental values for nobleman (Jun Zi). As Chen Tongsheng (2012, 77-80) pointed out:

Compared to pervious Ren values, Confucius's values of Ren made enormous progress in many regards. First of all, Confucius bestowed paramount importance to Ren by making it superior to other values. Confucius defined it as a genre values while keeping other values as attributes of Ren. Thus, the importance of Ren has surpassed that of other values and become the core content of Confucian ethics.

In Confucian values system, Ren, as a terminal value, can be gradually achieved through fulfilling other instrumental values. In so doing, Confucius established a bridge between the establishment of a person's terminal values and the development of his or her moral personality. In previous literatures, we found that contemporary researchers sometimes mixed up the concept of moral values with the concept of moral personality, and would simply use "ideal personality" or "noble personality" to generalize all Confucian values. In fact, there is no seamless connection between value orientation and personality formation, for values are only views and evaluative judgement at cognitive level, which may not naturally lead into corresponding behaviour, nor will it automatically grow into personality trait; instead, once formed, a 
personality may be more predictive to one's behaviour. Therefore, the concept of moral personality enhances the possible relations between ethical values and moral behaviour, but what may enhance the connection between ethical values and moral personality?

\subsection{Moral Personality Built Upon the Schema of Trust}

In psychological sense, personality is the sum total of ways in which an individual reacts to and interacts with others. We most often describe it in terms of the measurable traits a person exhibits. Among all the important determinants of personality, heredity is regarded more influential than environment, as Roccas et al. $(2002,789-801)$ discovered, there is indeed evidence linking personality to values, implying our values may be partly determined by our genetically transmitted traits. Confucius admitted the importance of heredity and argued that people indeed have inherent moral traits, as he once said, "a person who was born with Ren/benevolence is superior to others." However, Confucius emphasized more on the function of environment. Therefore, the fusion and fission of the value of Xin are resonant to his belief in personality development.

If an individual has desire to apply the ethical values of Xin into daily interactions, he or she are morally committed to such ethical values. When moral commitment is regarded as primary and essential factors resulting in correspondent behaviour, this individual possesses moral identity (Guo, Wang 2009). Moral identity has impact on one's selection of previous experience or knowledge to be stored as moral schemas.

Narvaez and Lapsley (2006) put forward a social cognition view on moral personality, and argued that moral personality is best seen as a chronic accessibility of certain moral schemas activated when interpreting social events. Some moral schemas will be readily accessible and easily activated in one's mental processing of social information, and will result in behavioural response. Similar to Jung's discussion of a natural process of introversion, this moral schema mechanism "leads to peculiar inner processes that change personality" (Jung 1958, 536). Hence, how a moral schema is formed and turned into action reflects the processes of fusion and fission of ethics, among which the most applicable is the value of Xin. Previous experience of being treated trustingly helped establish a schema, which would in turn help the subject become trustworthy and behave as a trusting character. Due to the chronic accessibility of some moral schemas, role models who would conduct spontaneous moral reasoning and take appropriate moral behavior, instead of going through very scrupulous decision-making steps.

Specific learning environment and experience can be harnessed to set up schema, which then influence our judgement, behaviour and personality. Therefore, in order to foster moral personality, Confucius emphasized the importance of learning environment, which enhance the fusion process of Xin 
(i.e. acquire safely and trustworthily the virtues from others) and he specified behavioral norms for different situations, which reinforce the fission process of Xin (i.e., apply what one learned onto others in a secured and accepted way). It is the implementation and enhancement of those specific ethical norms and ritual stipulations that actively facilitated the forming of moral schemas in his students. When one is at home, he needs to observe "social orders for the elderly and the young", and maintain filial to parents whenever coming back home; when one is with friends, he needs to "keep his words" and be trustworthy; when one is studying or working, he needs to "be slow in expressing ideas but swift in taking actions"; when one is socializing with unfamiliar people, he needs to remain "respectful, forgiving and generous"; when one is facing challenges, he needs to be "courageous and just".

Apart from these specific contents, we could find more vivid examples of teaching methods used by Confucius in the Analects. When Confucius was teaching his students, he tried different approaches to erecting moral schemas for his students, instead of simply introducing very abstract concepts and principles. In different situations, Confucius would select one specific theme, but would use different ways and perspectives to discuss the theme with different students. When each of the discussion was recorded, it is not difficult for us to find that with the same ethical issue or moral scenario, many different practices had been discussed; hence many moral schemas had been erected and stored in students' mind, which in current sense is the process of reinforcing the chronic accessibility of certain moral schemas. As Chen pointed out, "from those ancient works we may conclude that the teaching activities by Confucius to his students did not stop after class; instead, he used a lot more time after class to educate his students, such as during the time of informal meeting and chatting, climbing mountains, travelling, visiting friends and temples, worshipping ancestors, etc. nowhere is not the venue for teaching" (Chen 2012, 146). Besides, he would deliberately ask his students to observe the nature, use natural events or objects to analogize ethics and let them naturally gain insights from experiencing various social beings. Many of his comparative comments on famous historical figures could easily help students construct comparable moral schemas. As a result, in specific situations, by means of activating correspondent schema, students would apply relevant insights acquired from one example to other cases, and consequently, moral personality would be reinforced by the habitual tendency of perceiving, thinking, feeling and doing.

Now we see that, by using various learning scenarios, Confucius's method of teaching helped his students absorb all beneficial elements from otherness, integrate them into a moral self, and then encouraged students to apply what they fused from otherness back to others, insomuch that the schema of trust is built upon trustworthy social interactions and reinforced by trusting behaviour. 


\section{Conclusion}

The ultimate purpose of the discussion of ethics is for the freedom of existence of human beings, which however requires the subject to possess both persistent spirit for freedom and practical competence to apply such spirit to daily behaviour. Moral competence is the ability for free willpower to realize itself in moral behaviour. Such a competence vitalizes ethics and brings components of ethics into every personality.

In his book, the Courage to Create, the American existentialist psychologist, May Rollo $(2008,3-8)$ held the view that courage includes three kinds: physical courage with which one is able to feel, to listen and to be aware; moral courage with which one is able to perceive and to identify with others' suffering; social courage with which one is able to set up connection with others, to take the risks of losing one's own identity for social relations and to be committed to those open relations. At any rate, courage demands an authentic self, which can truly feel and admit any anxiety or happiness brought by social encounters and interactions. When encouraging the value of Xin, we are actually calling for the physical, moral and social courage to self, to others and even to otherness.

The anxiety of distrust we currently experience across the world is not an apprehension of unclear cause, nor an anxiety of nothingness. It is because of the shocks, conflicts and sudden rule-less conditions brought up by the encounter of distrustful self and untrustworthy otherness. Facing such tension, we have to accept the bewilderment and complexity of the anomy, and fight against the insignificance and the silence of this world until significance is rebuilt, the silent start to voice, nonexistence come to exist and new rules are restored. This is a process of seeking after the courage of Xin, the courage to be trustworthy and more importantly, the courage to trust.

The tension between the spontaneity and confinement of trust lead us to seek the possibility of building a society of honesty and integrity, a society full of people who are credible and trusting. Adler (2013) once said that civilization originated from man's physical limitations. Only the admission of limitations will overcome the limitations. Confinement may force spontaneity into more varied forms, and then different cultures resort to different ways to practice same ethical values. With the value of Ren at core, Confucian ethics formulate a set of important cultural means for Chinese people, and provide them with a shared experience of moral identity. The ethical value of Xin, once built into moral personality and reinforced as moral behaviour, may lead us to the discovery and acceptance of various anxiety from the encounter of self and otherness at physical, moral and social levels. With the courage to look for trust, we are brave to admit and accept the limitations of self, and actively establish connections with others. The courage to trust may be the simplest cure to the anomy of human society, if man is wise enough to seek after it. 


\section{References}

Adler, A. 2013. What Life Should Mean to You. Beijing: China Renmin University Press.

Bandura, A. 2015. Social Learning Theory. Beijing: China Renmin University Press.

Bem, D. J. 1967. "Self-Perception: An Alternative Interpretation of Cognitive Dissonance Phenomena." Psychological Review 1967(74): 183-200.

Chen, T. 2012. Ten Treatises on the Analects. Guangzhou: Jinan University Press. Fei, X. 2007. Rural China. Shanghai: Shanghai People Press.

Fukuyama, F. 2001. Trust: the Social Virtues and Creation of Prosperity. Haikou: Hainan Press.

Giddens, A. 2011. Consequences of Modernity. Nan Jing: Yi Lin Press.

Guo, B. \& Wang, Y. 2009. "Moral Personality: A New Research Topic for Moral Psychology." Journal of Southwest University (Social Science Edition) 4(35): 11-16.

Jung, C. G. 1958. Psychology and Religion: West and East. New York: Patheron Books.

Lind, G. $2015^{3}$ [2009]. Morality Can Be Taught. Berlin: Logos Verlag.

Luan, D. 2010. "Selected Commentary on Secluded Literatures." Literary Review 4: 186-195.

Narvaez, D. \& Lapsley, D. K. 2006. "Moral Chronicity and Social Information Processing: Tests of a Social Cognitive Approach to the Moral Personality." Journal of Research in Personality 40(6): 966-985.

Robbins, S. P. \& Judge, T. A. 2012. Organizational Behaviour. Beijing: Tsinghua University Press.

Roccas, S., Sagiv, L., Schwartz, S. H., \& Knafo, A. 2002. "The Big Five Personality Factors and Personal Values." Personality and Social Psychology Bulletin 28(6): 789-801.

Rokeach, M. 1973. The Nature of Human Values. New York: Free Press.

Rollo, M. 2008. The Courage to Create. Beijing: China Renmin Press.

Wan, J. 2009. Looking for Universal Ethics. Beijing: Peking University Press.

Wang, P. 1983. Annotation of Dai's Compilation of Rites. Beijing: China Book.

Yang, B. 1980. Annotation of the Analects. Beijing: China Book.

Zhang, Y. 2011. "On the Ranking of Values in Zhou-Qin Dynasty and Its Contemporary Significance." In: Wang, X. (Ed.) Compilation of Research Papers on Zhou-Qin Ethical Cultures and Moral Values. Baoji: Baoji University of Arts and Science: 321-327. 
Lei Kang (Guangdong University of Foreign Studies)

Ying Qiu (Guangdong University of Foreign Studies)

Tie Zheng (Guangdong University of Foreign Studies)

Anne Rubienska (Guangdong University of Foreign Studies)

\title{
Courage to Trust-A Discussion of Moral Personality Built Upon Confucian Ethics
}

\begin{abstract}
The value of Xin can find its origin in the Analects and other works by Confucius. Taking the perspectives from ethics and social psychology, this research aims to probe possible psychological basis for the value of Xin and discuss it from two aspects extracted from the Analects, i.e. being trustworthy and being able to trust. However, among Confucian ethics, the significance of the value of Xin is somehow underestimated, especially the willingness and ability to trust others. The discussion of Confucian ethical value of Xin focuses on the fusion and fission processes of turning the value of Xin into moral trait and behaviour, and extends into the development of moral personality. The fusion process of incorporating credibility into self and the fission process of transmitting trust into otherness reflect the importance of social interaction and learning experience in forming moral personality, as Confucius used to emphasized in his teaching. The driving force of these processes and the connection between ethical values and moral personality is the courage to be trusting, as well as trusty. A moral personality characterized by the courage to trust echoes the courage to connect self to others, which is enhanced by the effectively formed and activated schema of trust. Bringing Confucian ethics in the light of personality psychology, this multidisciplinary study may provide a new perspective to examine moral behaviour by unveiling the psychological link between ethical values and moral personality, which is the courage to be connected to others, i.e. the courage to trust.
\end{abstract}

Keywords: Confucian ethics, values, Xin, trust, moral personality, schema

Ethics in Progress (ISSN 2084-9257). Vol. 6 (2015). No. 1, pp. 11-25.

doi: 10.14746/eip.2015.2.2 